OPEN ACCESS

Edited by:

Andrew John Murton, University of Texas Medical Branch at Galveston, United States

Reviewed by:

Leonidas G. Karagounis, Nestlé Health Science, Switzerland

Daniel Moore,

University of Toronto, Canada

*Correspondence: Helen M. Roche

helen.roche@ucd.ie

Specialty section:

This article was submitted to Nutrition and Metabolism,

a section of the journal

Frontiers in Nutrition

Received: 21 January 2021 Accepted: 24 May 2021

Published: 21 June 2021

Citation:

de Marco Castro E, Murphy $\mathrm{CH}$ and Roche HM (2021) Targeting the Gut Microbiota to Improve Dietary Protein

Efficacy to Mitigate Sarcopenia.

Front. Nutr. 8:656730

doi: $10.3389 /$ fnut.2021.656730

\section{Targeting the Gut Microbiota to Improve Dietary Protein Efficacy to Mitigate Sarcopenia}

\author{
Elena de Marco Castro ${ }^{1}$, Caoileann H. Murphy ${ }^{1,2}$ and Helen M. Roche ${ }^{1,3 *}$ \\ ${ }^{1}$ Nutrigenomics Research Group, School of Public Health, Physiotherapy, and Sports Science, UCD Conway Institute, UCD \\ Institute of Food and Health, University College Dublin, Dublin, Ireland, ${ }^{2}$ Teagasc Food Research Centre, Ashtown, Dublin, \\ Ireland, ${ }^{3}$ Institute for Global Food Security, Queen's University Belfast, Belfast, United Kingdom
}

Sarcopenia is characterised by the presence of diminished skeletal muscle mass and strength. It is relatively common in older adults as ageing is associated with anabolic resistance (a blunted muscle protein synthesis response to dietary protein consumption and resistance exercise). Therefore, interventions to counteract anabolic resistance may benefit sarcopenia prevention and are of utmost importance in the present ageing population. There is growing speculation that the gut microbiota may contribute to sarcopenia, as ageing is also associated with [1) dysbiosis, whereby the gut microbiota becomes less diverse, lacking in healthy butyrate-producing microorganisms and higher in pathogenic bacteria, and [2) loss of epithelial tight junction integrity in the lining of the gut, leading to increased gut permeability and higher metabolic endotoxemia. Animal data suggest that both elements may impact muscle physiology, but human data corroborating the causality of the association between gut microbiota and muscle mass and strength are lacking. Mechanisms wherein the gut microbiota may alter anabolic resistance include an attenuation of gut-derived low-grade inflammation and/or the increased digestibility of protein-containing foods and consequent higher aminoacidemia, both in favour of muscle protein synthesis. This review focuses on the putative links between the gut microbiota and skeletal muscle in the context of sarcopenia. We also address the issue of plant protein digestibility because plant proteins are increasingly important from an environmental sustainability perspective, yet they are less efficient at stimulating muscle protein synthesis than animal proteins.

Keywords: protein digestibility, gut microbiota, sarcopenia, anabolic resistance, skeletal muscle, ageing, probiotic, leaky gut

\section{INTRODUCTION}

Sarcopenia refers to the adverse muscle changes that accrue overtime, resulting in the loss of skeletal muscle quantity and quality (1). The estimated prevalence of sarcopenia in community-dwelling individuals aged over 50 years old is $1-29 \%$ and $14-33 \%$ in those living in long-term care facilities (2). Sarcopenia represents a threat to healthy ageing, as it can lead to difficulty in performing tasks of daily living, dependence, and frailty $(3,4)$. In terms of the underlying biology, skeletal muscle mass is largely regulated by muscle protein turnover, which comprises muscle protein synthesis (MPS) and breakdown (MPB). Protein turnover fluctuates daily in response to anabolic (i.e., dietary 
protein ingestion, exercise, and, to a lesser extent, hormonal stimulation) and catabolic stimuli (e.g., reduced amino acid and insulin concentrations due to fasting) (5-7). Dietary amino acids (AA) act as building blocks for de novo MPS, and indispensable AA (IAA), particularly leucine, act as potent anabolic signals, promoting translation initiation, largely via activation of mTORC1 (8). During basal, postabsorptive conditions, MPB rates exceed MPS rates, resulting in a negative net muscle protein balance $(7,9)$. In healthy young adults, this transient muscle protein loss is compensated by the increase in MPS, after protein ingestion due to hyperaminoacidemia (10), and decrease in MPB due to hyperinsulinemia (11). However, ageing is associated with a blunted MPS response to anabolic stimuli, known as "anabolic resistance," which is one mechanism that can contribute to muscle loss overtime $(8,12)$.

Resistance exercise (13) and adequate nutritional intake, in particular energy and protein, are important factors contributing to sarcopenia prevention and treatment $(14,15)$. First, not only resistance exercise $(16,17)$ but also endurance exercise (18) sensitises the muscle to subsequent dietary protein ingestion, leading to a higher postprandial MPS response (13). In contrast, inactivity and muscle disuse, which tend to accompany ageing, show the opposite effect by desensitising the muscle to the anabolic effect of AA on MPS (19, 20). Second, higher protein intakes have been proposed to slow the loss of muscle mass in ageing (21) because higher protein (and leucine) intakes may compensate for anabolic resistance and induce an optimal postprandial MPS response $(8,15)$. Nevertheless, the interrelationship between dietary protein intake and long-term muscle and strength maintenance is complex. It is understood that low-protein intake may be a risk factor for sarcopenia since a greater amount of protein are required to stimulate MPS in the elderly $(8,12)$. However, many human dietary intervention studies have shown little or no impact of protein $(22,23)$, leucine (24-26), or IAA (27) supplementation on muscle mass and/or strength in non-exercising older adults. Therefore, resistance exercise, regulation of other nutrient sensors that modulate MPS aside from AA, and/or even greater amounts of protein supplementation/intake than those offered in this study may be essential tools to fight sarcopenia in healthy older adults. Given the age profile of the global population, we need to advance knowledge in relation to effective interventions to attenuate the age-related decline in muscle mass and function.

\section{EVIDENCE FOR THE GUT-MUSCLE AXIS}

Over the last two decades, there has been an exponential interest in the role of gut microbiota in health and disease (28). To this end, this review explores if and how this may play a role in relation to the gut-muscle axis within the context of sarcopenia. Before examining the emerging evidence in relation to a potential role of the gut microbiota in muscle mass and function (2931 ), it is important to acknowledge the wealth of knowledge in relation to factors that affect anabolic resistance $(8,12,32)$ and sarcopenia. Mechanisms involved in sarcopenia include poor nutrition (21), physical inactivity $(19,20)$, changes in hormone levels and sensitivity, especially insulin $(33,34)$, mitochondrial dysfunction (35), aberrant intermuscular and intramuscular fat deposition (36), and chronic low-grade inflammation $(37,38)$ [discussed here (39)].

From the microbiota perspective, the interrelationships between gut and muscle are not firmly established; nevertheless, there are some interesting developing perspectives. Backhed et al. (30) laid the foundation for recent research on the gut-muscle axis, showing that germ-free mice exhibit a lean phenotype, even on high-calorie, high-fat diets. Subsequent studies examining the skeletal muscle of germ-free (free of all microorganisms) vs. pathogen-free mice (free of pathogenic microorganisms) provided key insights into the gut-muscle axis (29). Compared with pathogen-free mice, germ-free mice had reduced skeletal muscle mass, strength, and IGF-1 local expression and increased local expression of genes associated with muscle atrophy (FoxO, Atrogin-1, Murf-1, and MyoD) (29). The explanation of the authors for the observed muscle mass reduction in germfree mice is an increase in MPB, rather than a significant reduction in MPS, as that activation of Akt-mTOR-S6k was unaffected in germ-free mice (29). Muscle protein turnover was not directly measured. It is important to note that, in humans, changes in MPS due to diet-mediated hyperaminoacidemia and resistance exercise, rather than alterations in $\mathrm{MPB}$, are better understood and believed to largely determine net protein balance and, ultimately, muscle size in nonpathogenic states $(40,41)$. Gut microbiota transplantation from pathogen-free mice into germ-free mice restored skeletal muscle mass, reduced muscle atrophy markers, improved oxidative metabolic capacity of the muscle, and elevated Rapsyn and Lrp4 expression, both of which are essential for neuromuscular junction maintenance $(29,42)$. Finally, they treated germ-free mice with a short-chain fatty acid (SCFA) blend of acetate, butyrate, and propionate, similar to what is produced by a healthy microbiota upon polysaccharides fermentation and partially reversed the skeletal muscle impairments and improved muscle strength (29). In addition, antibiotic-induced depletion of microbiota inmurine studies shows a reduction in muscle mass to a body mass ratio in comparison to the microbiota-containing control (4345). However, restoring their microbiota led to an increase of the muscle mass to the body mass ratio. We acknowledge the difficulty in translating these data from mice to humans (46) and that germ- and pathogen-free models are not a feasible study design to understand the effect of the gut microbiota on muscle in humans; however, germ-free mice models demonstrate the relevance of the gut in muscle mass and function in vivo.

\section{AGEING AND THE GUT MICROBIOTA-INSIGHTS FROM HUMAN STUDIES}

The gut microbiota of a typical older person displays reduced species richness and higher interindividual variability, together with less beneficial butyrate-producing bacteria and tight junction integrity, and a greater prevalence of pathogenic gramnegative bacteria (47-49). The fact that older people, especially 
the older and frail subjects $(31,50)$, have a distinct gut microbiota composition leads us and others $(31,51-56)$ to hypothesise the involvement of the gut microbiota in sarcopenia development.

Claesson et al. (31) carried out a cross-sectional study in 178 individuals aged $78 \pm 8$ years old and living in three different settings (community dwelling, short-term rehabilitation hospital care, and long-term residential care). They showed that the gut microbiota of the participant was clustered by living setting and was related to dietary intake (31). The "unfavourable microbiota profile," displaying lower diversity in the long-term residential care individuals, was correlated to frailty, comorbidities, poor nutritional status, and inflammation markers (31). Compared with community dwellers, short-term stay seniors showed a lower frequency of microbial genes for SCFA and higher serum markers of inflammation (31). The differences in dietary intake, medication use, and clinical status between the subgroups had an effect on modulating the gut microbiota $(52,57,58)$ and may have acted as confounding variables that contributed to the associations observed between health and gut microbiota composition in the study (31). Other studies also suggest that physical frailty is inversely related to gut microbiota biodiversity and the relative abundance of a number of key taxa (31, 50, 52, 59-63). However, even if these studies reduced or excluded confounding factors, it is not possible in observational study designs to establish a cause-effect relationship between a specific gut microbiota composition or taxa and healthy ageing or longevity. In a recent attempt to evaluate a causative role for the gut microbiota in body composition and strength, germ-free mice were colonised with the gut microbiota of high- and lowfunctioning older adults (64). Compellingly, muscle strength, but not lean mass or endurance, was significantly higher in mice colonised with microbiota from high- vs. low-functioning older adults (64).

\section{PROBIOTIC AND THE GUT MICROBIOTA}

Probiotics can be defined as "live microorganisms that when administered in adequate amounts confer a health benefit to the host" (65). Recent evidence points towards probiotic supplementation as a plausible nutrition intervention to improve muscle mass and/or function (66-73) and to help prevent sarcopenia. To our knowledge, there is no evidence in relation to the impact of probiotic supplementation on MPS, but a possible role may be a probiotic-directed improvement of protein digestibility, gut permeability, and SCFA production. While these mechanisms do not inherently alter the protein composition of the source (e.g., IAA or leucine content), better digestion may increase postprandial aminoacidemia, and improved gut permeability may reduce chronic inflammation, both in favour of MPS (Figure 1).

\section{PROBIOTIC AND THE GUT-MUSCLE AXIS}

Bindels et al. (66) led one of the pioneer studies on gut microbiota modulation as a way to alter muscle in leukemic mice. Oral probiotic supplementation (Lactobacillus reuteri and
Lactobacillus gasseri, but not Lactobacillus acidophilus) restored gut microbiota health from a baseline status of dysbiosis, reduced serum levels of pro-inflammatory cytokines, and increased muscle mass (66). In another murine cancer model, $L$. reuteri supplementation reduced systemic inflammation and preserved muscle mass (67). In healthy young mice without systemic inflammation, probiotic Lactobacillus plantarum supplementation not only improved lean mass but also muscle function (68). A series of recent reviews (74-78) and original studies (69-73) have investigated the impact of probiotic supplementation on lean mass and physical performance in humans. After probiotic supplementation, some studies in athletes (predominately males) showed improvements in muscle strength, power, and exercise recovery (69-72), but none observed significant alterations in body lean mass (69-73). The extent to which probiotic supplementation is able to alter the intestinal gut microbiota is under debate $(79,80)$. However, a proprietary form of Bacillus coagulans has demonstrated an advantageous spore-forming ability to survive the harsh condition of the stomach, which enables it to create a healthier gut microbiota composition in the elderly (81) and aid with the digestion of plant-based proteins in a validated in vitro model of the stomach and small intestine (82).

In humans, only two studies, to our knowledge, have investigated the effect of probiotic supplementation on aminoacidemia, following pea (83) and milk (84) protein ingestion. After 2 weeks of protein supplementation with or without added probiotics, the participants reported to the laboratory, and blood samples were taken in the fasted state and following the ingestion of their respective supplement. In one study, 15 physically active young men consumed isolated pea protein with or without probiotic Lactobacillus paracasei (83). In the other study, 30 young males and females ingested milk protein concentrate with or without B. coagulans (84). Both studies used postprandial maximum systemic AA concentration $\left(\mathrm{C}_{\max }\right)$ and area under the curve (AUC) as proxy measurements for AA digestion and absorption. $\mathrm{C}_{\max }$ and AUC were higher after protein and probiotic co-ingestion in comparison with protein alone in both studies $(83,84)$. Such an increase in aminoacidemia may improve the muscle anabolic response to dietary protein (70), although that outcome was not determined.

\section{PUTATIVE MECHANISM 1: PROBIOTICS AND PROTEIN DIGESTIBILITY}

In addition to total protein intake, the quality of the protein consumed in the diet is another important consideration for muscle mass preservation with age. Plant proteins are increasingly important from an environmental sustainability perspective (85), yet they are less efficient at stimulating muscle protein synthesis than animal proteins at the same protein dose (86). Plant vs. animal proteins show lower digestibility (45$80 \%$ vs. $>90 \%$, respectively) in both young and old individuals due to high levels of insoluble fibres and/or anti-nutritional factors (87-89). Anti-nutritional factors present endogenously, like trypsin inhibitors in grain legumes or tannins in cereals 


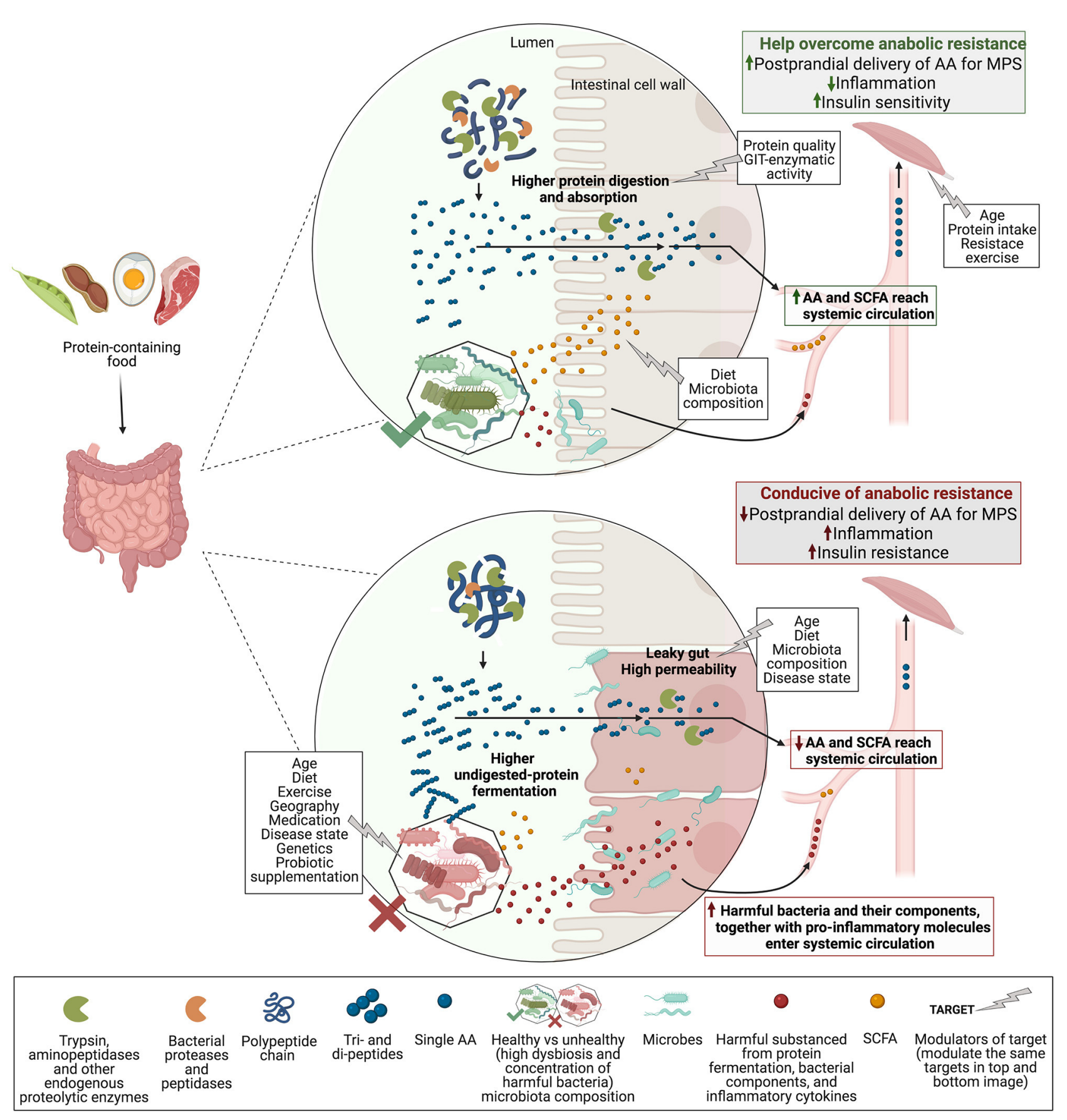

FIGURE 1 | Proposed the gut microbiota role in protein digestion and absorption, and related MPS response. Polypeptides from protein-containing foods enter the duodenum and are cleaved by enzymes into di- and tripeptides, and some single AA, which are absorbed by enterocytes (intestinal cell wall). Aminopeptidases of enterocytes cleave di- and tripeptides into single AA that can now enter systemic circulation after first-pass splanchnic retention. In the lumen, enzymes of gut microbes or probiotics may aid with the polypeptide and shorter peptides cleavage to increase AA delivery to the bloodstream. Undigested peptides reach the colon and are fermented by the gut microbiota to release molecules like ammonia and hydrogen sulphide (harmful), and SCFA (in lesser amounts, SCFAs are mainly ferments of undigested carbohydrates). A healthy gut microbiota composition (high concentration of beneficial microbes and diversity) may release higher amounts of SCFA and is better able to control the translocation of harmful substances from the lumen into circulation. SCFA can improve gut permeability and may positively modulate muscle biology. Reduced translocation of proinflammatory molecules is linked to lower systemic inflammation and may positively influence insulin sensitivity in the muscle. Opposingly, unhealthy gut microbiota is associated with a leaky gut, which is less able to regulate the harmful translocation into the bloodstream of microbes (e.g., Bacteroides sp.) and their components (e.g., LPS), as well as proinflammatory cytokines, all likely to be found in an "unhealthy" GIT. This leads to 
FIGURE 1 | low-grade chronic systemic inflammation that may contribute to insulin and anabolic resistance in the muscle. Therefore, healthy gut microbiota may improve protein digestion and absorption by increasing peptide cleavage, and, in addition, promote SCFA production and reduce protein fermentation and the "leaky gut." As a result, more AA and SCFA, and less gut-derived harmful molecules enter systemic circulation, increasing the postprandial delivery of AA to the muscle and reducing systemic and local inflammation, both in favour of MPS. Abbreviations: MPS, muscle protein synthesis; AA, amino acids; SCFA, short-chain fatty acids; LPS, lipopolysaccharide; GIT, gastrointestinal tract-created with BioRender.com.

(90), or are formed during excessive heat and/or alkaline processing, like Maillard compounds in milk, and may reduce protein bioavailability $(91,92)$. Contrarily, the processing of dietary plant proteins (gentle heating, soaking, germination, and fermentation) may have a positive effect on digestibility (93-95). This is important for plant proteins because poor digestibility results in lower AA absorption and thus reduced AA availability for MPS (96). Although the difference between protein digestion and absorption kinetics in older vs. young individuals does not appear to be the limiting factor for the observed difference in MPS $(97,98)$, improving plant protein digestibility would enhance the delivery of AA to circulation (and of special interest IAA). This has already been identified in young healthy humans for pea protein (83) and milk protein (84) with probiotic coingestion, as mentioned above. An explanation for this could be the release of proteases and peptidases by the probiotic to facilitate protein digestion in the small intestine, although this hypothesis would have been better supported if the protein had been ingested in its raw form (as part of the intact food source; peas and milk) and not as a protein isolate. This is particularly relevant in older individuals as they need more protein per meal to maximise the postprandial MPS response (99) and, thus, to preserve muscle mass with age (100). An improvement in protein digestibility would imply that older people could reduce the net amount of protein consumption per meal for the same MPS effect, which is crucial, given their reduced appetite (101).

\section{PUTATIVE MECHANISM 2: PROBIOTICS AND THE LEAKY GUT}

The intestinal barrier is the key to maintaining gut integrity, preventing leakage of bacterial cells and/or their proinflammatory toxins into the bloodstream (102). The "leaky gut" hypothesis proposes that as a result of intestinal barrier breakdown, its permeability increases and is less able to regulate the translocating of harmful substances, triggering the immune system and inflammatory responses $(102,103)$. In this review, we speculate that the leaky gut may be associated with sarcopenia since low-grade chronic inflammation in older adults is one of the factors believed to contribute to anabolic resistance and thus sarcopenia development (38).

Rodent studies indicate that ageing is associated with a leaky gut via gut-derived metabolic endotoxemia and low-grade chronic inflammation (104-106). Poor mucosal barrier function and increased inflammation have also been reported in aged vs. young monkeys $(103,107)$. Qi et al. (108) measured zonulin, a physiologic regulator of intestinal permeability (109), in healthy young (18-30 years, $n=19)$ and old ( $\geq 70$ years, $n=18$ ) adults. Serum zonulin concentrations were significantly higher in older vs. younger adults, were positively associated with proinflammatory cytokine levels (TNF- $\alpha$ and IL-6), and were negatively associated with physical activity levels and skeletal muscle strength (108). Furthermore, the serum microbiota of young (20-35 years, $n=24)$ vs. old $(60-75$ years $n=24)$ individuals differs and is linked to markers of age-related systemic inflammation (110). While these data support the role of a leaky gut in age-directed inflammation and frailty, data from Valentini et al. (111) concluded that small intestinal barrier integrity is not altered in healthy ageing. However, it supported that low-grade chronic inflammation, which is common in older adults $(38,112)$, compromises intestinal barrier permeability (111). Therefore, one may question whether age-directed lowgrade chronic inflammation is the cause or the result of gut barrier breakdown $(113,114)$.

It could be hypothesised that, irrespective of age, "fixing" a leaky gut may enhance muscle function by reducing the amount of detrimental microbial products (e.g., LPS and indoxyl sulphate) that access systemic circulation. These harmful substances are known to trigger low-grade systemic inflammation, insulin resistance, and glucose intolerance in murine skeletal muscle $(115,116)$. They have also been reported to increase NFKB activity and JNK phosphorylation, blunt AMPK phosphorylation in skeletal muscle tissue of patients with type 2 diabetes (117), and reduce insulin sensitivity in LPS-treated human muscle cells (118).

Emerging evidence points towards a potential role for probiotic-mediated alleviation of the leaky gut. Probiotic supplementation improved markers of an intestinal barrier and inflammation in trained men under exercise stress in a randomised clinical trial (119), in rodents $(120,121)$, and in a porcine intestinal epithelial cell line (IPEC-J2) (122). However, a systematic review from 2013 that included human studies measuring parameters of epithelial barrier function had evidence for and against probiotic supplementation (123). Note that the study population and probiotics employed were high in heterogeneity. Therefore, more studies need to evaluate the effect of microbiota modulation on the leaky gut and resulting microbiota-derived inflammatory markers in circulation and their effect on skeletal human muscle.

\section{PUTATIVE MECHANISM 3: PROBIOTICS AND MUSCLE NUTRIENT SENSORS}

Another putative link between gut microbiota modulation and the muscle could be regulated by muscle nutrient sensors, which are gut microbiota by-products, mainly SCFAs (29), could alter muscle biology [reviewed here $(124,125)]$. Probiotic bacteria are known producers of SCFAs $(45,126,127)$. Emerging evidence 
from young germ-free mice fed with SCFAs shows an increase in skeletal muscle mass and strength compared with the untreated control (29). Also, sodium butyrate-supplemented high-fat dietfed young mice exhibited a reduction in skeletal muscle insulin resistance vs. their non-supplemented counterparts (128). Similarly, aged mice under a 10 -month sodium butyratesupplemented diet treatment showed an increase in muscle mass to body mass ratio when compared with the nonsupplemented control (129). Interestingly, SCFA-producing bacteria include Barnesiella and Prevotellaceae and are both found in higher concentration in high- vs. low-functioning older adults, characterised based on the percentage of body lean mass and physical functioning (64). These studies show a strong association between SCFA and muscle mass and strength; however, whether this link is casual in humans and its mechanism is not known.

\section{CONCLUSION AND FUTURE PERSPECTIVES}

Ageing is often associated with a reduction in muscle mass and function together with a reduction in abundance, resilience, and diversity of the gut microbiota $(31,50,61,62)$. While emerging evidence supports a putative link between the gut and the muscle that could be a potential target for the prevention and treatment of sarcopenia, a causal relationship between the gut microbiota and muscle protein synthesis has not yet been established in humans, albeit evidence from murine models is strong (29). However, the data examined in this review may underpin the hypothesis that a healthy and diverse gut microbiota in an elderly cohort, potentially modulated via probiotic supplementation, may improve age-associated muscle decline, mechanistically, (1) by improving the intestinal cell wall integrity, thus reducing metabolic endotoxemia and consequential inflammation linked to insulin resistance and anabolic resistance (also potentially modulated by short-chain fatty acids), and/or (2) by improving dietary protein digestion and absorption via gut-bacterial enzymatic activity, leading to enhanced amino acid availability

\section{REFERENCES}

1. Cruz-Jentoft AJ, Bahat G, Bauer J, Boirie Y, Bruyère $O$, Cederholm T, et al. Sarcopenia: revised European consensus on definition and diagnosis. Age Ageing. (2019) 48:16-31. doi: 10.1093/ageing/afz046

2. Cruz-Jentoft AJ, Landi F, Schneider SM, Zuniga C, Arai H, Boirie Y, et al. Prevalence of and interventions for sarcopenia in ageing adults: a systematic review. Report of the International Sarcopenia Initiative (EWGSOP and IWGS). Age Ageing. (2014) 43:748-59. doi: 10.1093/ageing/afu115

3. Bianchi L, Ferrucci L, Cherubini A, Maggio M, Bandinelli S, Savino E, et al. The predictive value of the EWGSOP definition of sarcopenia: results from the InCHIANTI study. J Gerontol A Biol Sci Med Sci. (2016) 71:25964. doi: 10.1093/gerona/glv129

4. Trombetti A, Reid KF, Hars M, Herrmann FR, Pasha E, Phillips EM, et al. Age-associated declines in muscle mass, strength, power, and physical performance: impact on fear of falling and quality of life. Osteoporos Int. (2016) 27:463-71. doi: 10.1007/s00198-015-3236-5

5. Pacy PJ, Price GM, Halliday D, Quevedo MR, Millward DJ. Nitrogen homoeostasis in man: the diurnal responses of protein synthesis and for de novo protein synthesis. These points are relevant in the context of healthy ageing in the present ever-growing older population (130), where enhancing and preserving physical strength, mobility, and independence are of utmost importance. The review also highlights the need for a greater understanding in relation to the area of nutrition that deals with sarcopenia prevention and treatment based on protein supplementation research disagreements on muscle mass and strength in older adults. Within this research gap, we acknowledge that the plant protein industry is booming, stemmed from environmental, ethical, and health interests (131). Even though plant protein may be less effective for preserving muscle mass in ageing, this presents a research opportunity to clearly define the efficacy of plant proteins on de novo protein synthesis in humans, which may or may not be affected by the gut microbiota. Overall, improving the digestibility and absorption of alternative protein sources and their ability to stimulate muscle protein synthesis will ease the environmental and nutritional challenges of the future global population while also favouring functional ageing.

\section{AUTHOR CONTRIBUTIONS}

EM drafted the manuscript with advice from CM and HR. CM and HR provided critical revisions. All the authors approved the final version of the manuscript.

\section{FUNDING}

EM was supported by the Irish Research Council EmploymentBased (IRCEB) Ph.D. Scholarship Scheme, Project ID EBPPG/2018/137. CM was supported by the Department of Agriculture, Food, and the Marine Food Institutional Research Measure Grants NUTRIMAL Novel Nutritional Solutions for the Prevention of Malnutrition (Grant no. 14F822). HR was supported by funding from the Joint Programing Initiative Healthy Diet for a Healthy Life (JPI HDHL) EU Food Biomarkers Alliance FOODBALL with Science Foundation Ireland (14/JPIHDHL/B3076). degradation and amino acid oxidation to diets with increasing protein intakes. Clin Sci. (1994) 86:103-18. doi: 10.1042/cs0860103

6. Burd NA, West DW, Moore DR, Atherton PJ, Staples AW, Prior T, et al. Enhanced amino acid sensitivity of myofibrillar protein synthesis persists for up to $24 \mathrm{~h}$ after resistance exercise in young men. J Nutr. (2011) 141:56873. doi: 10.3945/jn.110.135038

7. Phillips SM, Hartman JW, Wilkinson SB. Dietary protein to support anabolism with resistance exercise in young men. J Am Coll Nutr. (2005) 24:134S-9S. doi: 10.1080/07315724.2005.10719454

8. Katsanos CS, Kobayashi H, Sheffield-Moore M, Aarsland A, Wolfe RR. A high proportion of leucine is required for optimal stimulation of the rate of muscle protein synthesis by essential amino acids in the elderly. Am J Physiol Endocrinol Metab. (2006) 291:E381-E7. doi: 10.1152/ajpendo.00488.2005

9. Rennie MJ, Wackerhage H, Spangenburg EE, Booth FW. Control of the size of the human muscle mass. Annu Rev Physiol. (2004) 66:799828. doi: 10.1146/annurev.physiol.66.052102.134444

10. Groen BB, Horstman AM, Hamer HM, De Haan M, Van Kranenburg J, Bierau J, et al. Post-prandial protein handling: you are what you just ate. PLoS ONE. (2015) 10:e0141582. doi: 10.1371/journal.pone.0141582 
11. Bohé J, Low JA, Wolfe RR, Rennie MJ. Rapid report: latency and duration of stimulation of human muscle protein synthesis during continuous infusion of amino acids. J Physiol. (2001) 532:575-9. doi: 10.1111/j.1469-7793.2001.0575f.x

12. Cuthbertson D, Smith K, Babraj J, Leese G, Waddell T, Atherton P, et al. Anabolic signaling deficits underlie amino acid resistance of wasting, aging muscle. FASEB J. (2005) 19:422-4. doi: 10.1096/fj.04-2640fje

13. Peterson MD, Sen A, Gordon PM. Influence of resistance exercise on lean body mass in aging adults: a meta-analysis. Med Sci Sports Exerc. (2011) 43:249. doi: 10.1249/MSS.0b013e3181eb6265

14. Weinheimer EM, Sands LP, Campbell WW. A systematic review of the separate and combined effects of energy restriction and exercise on fat-free mass in middle-aged and older adults: implications for sarcopenic obesity. Nutr Rev. (2010) 68:375-88. doi: 10.1111/j.1753-4887.2010.00298.x

15. Mitchell CJ, Milan AM, Mitchell SM, Zeng N, Ramzan F, Sharma P, et al. The effects of dietary protein intake on appendicular lean mass and muscle function in elderly men: a 10-wk randomized controlled trial. Am J Clin Nutr. (2017) 106:1375-83. doi: 10.3945/ajcn.117.160325

16. Phillips SM, Tipton KD, Aarsland A, Wolf SE, Wolfe RR. Mixed muscle protein synthesis and breakdown after resistance exercise in humans. Am J Physiol Endocrinol Metab. (1997) 273:e99-107. doi: 10.1152/ajpendo.1997.273.1.E99

17. Witard OC, Tieland M, Beelen M, Tipton KD, Van Loon LJ, Koopman R. Resistance exercise increases postprandial muscle protein synthesis in humans. Med Sci Sports Exerc. (2009) 41:144-54. doi: 10.1249/MSS.0b013e3181844e79

18. Pennings B, Koopman R, Beelen M, Senden JM, Saris WH, Van Loon LJ. Exercising before protein intake allows for greater use of dietary proteinderived amino acids for de novo muscle protein synthesis in both young and elderly men. Am J Clin Nutr. (2011) 93:322-31. doi: 10.3945/ajcn.2010.29649

19. Dirks ML, Wall BT, Nilwik R, Weerts DH, Verdijk LB, van Loon LJ. Skeletal muscle disuse atrophy is not attenuated by dietary protein supplementation in healthy older men. $J$ nutr. (2014) 144:1196-203. doi: 10.3945/jn.114.194217

20. Wall BT, Snijders T, Senden JM, Ottenbros CL, Gijsen AP, Verdijk LB, et al. Disuse impairs the muscle protein synthetic response to protein ingestion in healthy men. J Clin Endocrinol Metab. (2013) 98:487281. doi: 10.1210/jc.2013-2098

21. Houston DK, Nicklas BJ, Ding J, Harris TB, Tylavsky FA, Newman $\mathrm{AB}$, et al. Dietary protein intake is associated with lean mass change in older, community-dwelling adults: the health, aging, and body composition (Health ABC) study. Am J Clin Nutr. (2008) 87:1505. doi: 10.1093/ajcn/87.1.150

22. Zhu K, Kerr DA, Meng X, Devine A, Solah V, Binns CW, et al. Two-year whey protein supplementation did not enhance muscle mass and physical function in well-nourished healthy older postmenopausal women. J Nutr. (2015) 145:2520-6. doi: 10.3945/jn.115.218297

23. Kirk B, Mooney K, Cousins R, Angell P, Jackson M, Pugh JN, et al. Effects of exercise and whey protein on muscle mass, fat mass, myoelectrical muscle fatigue and health-related quality of life in older adults: a secondary analysis of the Liverpool Hope University-Sarcopenia Ageing Trial (LHU-SAT). Eur J Appl Physiol. (2020) 120:493-503. doi: 10.1007/s00421-019-04293-5

24. Verhoeven S, Vanschoonbeek K, Verdijk LB, Koopman R, Wodzig WK, Dendale $\mathrm{P}$, et al. Long-term leucine supplementation does not increase muscle mass or strength in healthy elderly men. Am J Clin Nutr. (2009) 89:1468-75. doi: 10.3945/ajcn.2008.26668

25. Leenders M, Verdijk LB, van der Hoeven L, van Kranenburg J, Hartgens F, Wodzig WK, et al. Prolonged leucine supplementation does not augment muscle mass or affect glycemic control in elderly type 2 diabetic men. J Nutr. (2011) 141:1070-6. doi: 10.3945/jn.111.138495

26. Murphy $\mathrm{CH}$, Flanagan EM, De Vito G, Susta D, Mitchelson KAJ, de Marco Castro E, et al. Does supplementation with leucine-enriched protein alone and in combination with fish-oil-derived n-3 PUFA affect muscle mass, strength, physical performance, and muscle protein synthesis in wellnourished older adults? A randomized, double-blind, placebo-controlled trial. Am J Clin Nutr. (2021). doi: 10.1093/ajcn/nqaa449

27. Kim HK, Suzuki T, Saito K, Yoshida H, Kobayashi H, Kato H, et al. Effects of exercise and amino acid supplementation on body composition and physical function in community-dwelling elderly Japanese sarcopenic women: a randomized controlled trial. J Am Geriatr Soc. (2012) 60:1623. doi: 10.1111/j.1532-5415.2011.03776.x

28. Huang $\mathrm{X}$, Fan $\mathrm{X}$, Ying J, Chen S. Emerging trends and research foci in gastrointestinal microbiome. J Transl Med. (2019) 17:1-11. doi: 10.1186/s12967-019-1810-x

29. Lahiri S, Kim H, Garcia-Perez I, Reza MM, Martin KA, Kundu P, et al. The gut microbiota influences skeletal muscle mass and function in mice. Sci Transl Med. (2019) 11(502). doi: 10.1126/scitranslmed.aan5662

30. Bäckhed F, Manchester JK, Semenkovich CF, Gordon JI. Mechanisms underlying the resistance to diet-induced obesity in germ-free mice. Proc Natl Acad Sci USA. (2007) 104:979-84. doi: 10.1073/pnas.0605374104

31. Claesson MJ, Jeffery IB, Conde S, Power SE, O'Connor EM, Cusack S, et al. Gut microbiota composition correlates with diet and health in the elderly. Nature. (2012) 488:178-84. doi: 10.1038/nature11319

32. Kumar V, Selby A, Rankin D, Patel R, Atherton P, Hildebrandt W, et al. Age-related differences in the dose-response relationship of muscle protein synthesis to resistance exercise in young and old men. J Physiol. (2009) 587:211-7. doi: 10.1113/jphysiol.2008.164483

33. Rasmussen BB, Fujita S, Wolfe RR, Mittendorfer B, Roy M, Rowe VL, et al. Insulin resistance of muscle protein metabolism in aging. FASEB J. (2006) 20:768-9. doi: 10.1096/fj.05-4607fje

34. Abdulla H, Smith K, Atherton PJ, Idris I. Role of insulin in the regulation of human skeletal muscle protein synthesis and breakdown: a systematic review and meta-analysis. Diabetologia. (2016) 59:4455. doi: 10.1007/s00125-015-3751-0

35. Petersen KF, Befroy D, Dufour S, Dziura J, Ariyan C, Rothman DL, et al. Mitochondrial dysfunction in the elderly: possible role in insulin resistance. Science. (2003) 300:1140-2. doi: 10.1126/science.1082889

36. Zoico E, Rossi A, Di Francesco V, Sepe A, Olioso D, Pizzini F, et al. Adipose tissue infiltration in skeletal muscle of healthy elderly men: relationships with body composition, insulin resistance, and inflammation at the systemic and tissue level. J Gerontol Ser A Biol Sci Med Sci. (2010) 65:295-9. doi: 10.1093/gerona/glp155

37. Wåhlin-Larsson B, Wilkinson DJ, Strandberg E, Hosford-Donovan A, Atherton PJ, Kadi F. Mechanistic links underlying the impact of C-reactive protein on muscle mass in elderly. Cell Physiol Biochem. (2017) 44:26778. doi: 10.1159/000484679

38. Bano G, Trevisan C, Carraro S, Solmi M, Luchini C, Stubbs B, et al. Inflammation and sarcopenia: A systematic review and metaanalysis. Maturitas. (2017) 96:10-5. doi: 10.1016/j.maturitas.2016. 11.006

39. Murphy C, Roche H. Nutrition and physical activity countermeasures for sarcopenia: time to get personal? Nutr Bull. (2018) 43:37487. doi: $10.1111 /$ nbu. 12351

40. Tipton KD, Hamilton DL, Gallagher IJ. Assessing the role of muscle protein breakdown in response to nutrition and exercise in humans. Sports Med. (2018) 48:53-64. doi: 10.1007/s40279-017-0845-5

41. Volpi E, Kobayashi H, Sheffield-Moore M, Mittendorfer B, Wolfe RR. Essential amino acids are primarily responsible for the amino acid stimulation of muscle protein anabolism in healthy elderly adults. Am J Clin Nutr. (2003) 78:250-8. doi: 10.1093/ajcn/78.2.250

42. Barik A, Lu Y, Sathyamurthy A, Bowman A, Shen C, Li L, et al. LRP4 is critical for neuromuscular junction maintenance. J Neurosci. (2014) 34:13892-905. doi: 10.1523/JNEUROSCI.1733-14.2014

43. Manickam R, Oh HYP, Tan CK, Paramalingam E, Wahli W. Metronidazole causes skeletal muscle atrophy and modulates muscle chronometabolism. Int J Mol Sci. (2018) 19:2418. doi: 10.3390/ijms19082418

44. Nay K, Jollet M, Goustard B, Baati N, Vernus B, Pontones M, et al. Gut bacteria are critical for optimal muscle function: a potential link with glucose homeostasis. Am J Physiol Endocrinol Metab. (2019) 317:e15871. doi: 10.1152/ajpendo.00521.2018

45. Okamoto T, Morino K, Ugi S, Nakagawa F, Lemecha M, Ida S, et al. Microbiome potentiates endurance exercise through intestinal acetate production. Am J Physiol Endocrinol Metab. (2019) 316:e95666. doi: 10.1152/ajpendo.00510.2018

46. Rennie MJ, Selby A, Atherton P, Smith K, Kumar V, Glover EL, et al. Facts, noise and wishful thinking: muscle protein turnover in aging 
and human disuse atrophy. Scand J Med Sci Sports. (2010) 20:59. doi: 10.1111/j.1600-0838.2009.00967.x

47. Jeffery IB, Lynch DB, O'toole PW. Composition and temporal stability of the gut microbiota in older persons. ISME J. (2016) 10:170. doi: 10.1038/ismej.2015.88

48. Claesson MJ, Cusack S, O'Sullivan O, Greene-Diniz R, de Weerd H, Flannery E, et al. Composition, variability, and temporal stability of the intestinal microbiota of the elderly. Proc Natl Acad Sci USA. (2011) 108(Suppl. 1):458691. doi: 10.1073 /pnas.1000097107

49. Lee SY, Kang HJ, Kang JH, Cho MG, Jang HW, Kim BK, et al. Differences in the gut microbiota between young and elderly persons in Korea. Nutr Res. (2021) 87:31-40. doi: 10.1016/j.nutres.2020.12.013

50. Verdi S, Jackson MA, Beaumont M, Bowyer RC, Bell JT, Spector $\mathrm{TD}$, et al. An investigation into physical frailty as a link between the gut microbiome and cognitive health. Front Aging Neurosci. (2018) 10:398. doi: 10.3389/fnagi.2018.00398

51. Picca A, Fanelli F, Calvani R, Mulè G, Pesce V, Sisto A, et al. Gut dysbiosis and muscle aging: searching for novel targets against sarcopenia. Mediators Inflamm. (2018):7026198. doi: 10.1155/2018/7026198

52. Ticinesi A, Milani C, Lauretani F, Nouvenne A, Mancabelli L, Lugli GA, et al. Gut microbiota composition is associated with polypharmacy in elderly hospitalized patients. Sci Rep. (2017) 7:1-11. doi: 10.1038/s41598-017-10734-y

53. Ni Lochlainn M, Bowyer RC, Steves CJ. Dietary protein and muscle in aging people: the potential role of the gut microbiome. Nutrients. (2018) 10:929. doi: 10.3390/nu10070929

54. De Sire R, Rizzatti G, Ingravalle F, Pizzoferrato M, Petito V, Lopetuso L, et al. Skeletal muscle-gut axis: emerging mechanisms of sarcopenia for intestinal and extra intestinal diseases. Minerva Gastroenterol Dietol. (2018) 64:351-62. doi: 10.23736/S1121-421X.18.02511-4

55. Grosicki GJ, Fielding RA, Lustgarten MS. Gut microbiota contribute to age-related changes in skeletal muscle size, composition, and function: biological basis for a gut-muscle axis. Calcif Tissue Int. (2018) 102:43342. doi: 10.1007/s00223-017-0345-5

56. Lustgarten MS. The role of the gut microbiome on skeletal muscle mass and physical function: 2019 update. Front Physiol. (2019) 10:1435. doi: $10.3389 /$ fphys.2019.01435

57. Yatsunenko T, Rey FE, Manary MJ, Trehan I, Dominguez-Bello MG, Contreras $M$, et al. Human gut microbiome viewed across age and geography. Nature. (2012) 486:222-7. doi: 10.1038/nature11053

58. Milani C, Ferrario C, Turroni F, Duranti S, Mangifesta M, Van Sinderen D, et al. The human gut microbiota and its interactive connections to diet. J Hum Nutr Diet. (2016) 29:539-46. doi: 10.1111/jhn.12371

59. Jackson MA, Jeffery IB, Beaumont M, Bell JT, Clark AG, Ley RE, et al. Signatures of early frailty in the gut microbiota. Genome Med. (2016) 8:111. doi: 10.1186/s13073-016-0262-7

60. Maffei VJ, Kim S, Blanchard IV E, Luo M, Jazwinski SM, Taylor CM, et al. Biological aging and the human gut microbiota. J Gerontol Ser A Biomed Sci Med Sci. (2017) 72:1474-82. doi: 10.1093/gerona/glx042

61. Haran JP, Bucci V, Dutta P, Ward D, McCormick B. The nursing home elder microbiome stability and associations with age, frailty, nutrition and physical location. J Med Microbiol. (2018) 67:40. doi: 10.1099/jmm.0.000640

62. Ogawa T, Hirose Y, Honda-Ogawa M, Sugimoto M, Sasaki S, Kibi M, et al. Composition of salivary microbiota in elderly subjects. Sci Rep. (2018) 8:1-9. doi: 10.1038/s41598-017-18677-0

63. Theou O, Jayanama K, Fernández-Garrido J, Buigues C, Pruimboom L, Hoogland A, et al. Can a prebiotic formulation reduce frailty levels in older people? J Frailty Aging. (2019) 8:48-52. doi: 10.14283/jfa.2018.39

64. Fielding RA, Reeves AR, Jasuja R, Liu C, Barrett BB, Lustgarten MS. Muscle strength is increased in mice that are colonized with microbiota from high-functioning older adults. Exp Gerontol. (2019) 127:110722. doi: 10.1016/j.exger.2019.110722

65. Morelli L, Capurso L. FAO/WHO Guidelines on Probiotics: 10 Years Later. J Clin Gastroenterol. (2012) 46:s1-2. doi: 10.1097/MCG.0b013e318269fdd5

66. Bindels LB, Beck R, Schakman O, Martin JC, De Backer F, Sohet FM, et al. Restoring specific lactobacilli levels decreases inflammation and muscle atrophy markers in an acute leukemia mouse model. PLoS ONE. (2012) 7:e37971. doi: 10.1371/journal.pone.0037971
67. Varian BJ, Gourishetti S, Poutahidis T, Lakritz JR, Levkovich T, Kwok C, et al. Beneficial bacteria inhibit cachexia. Oncotarget. (2016) 7:1180316. doi: 10.18632 /oncotarget.7730

68. Chen Y-M, Wei L, Chiu Y-S, Hsu Y-J, Tsai T-Y, Wang M-F, et al. Lactobacillus plantarum TWK10 supplementation improves exercise performance and increases muscle mass in mice. Nutrients. (2016) 8:205. doi: $10.3390 /$ nu 8040205

69. Georges J, Lowery RP, Yaman G, Kerio C, Ormes J, McCleary SA, et al. The effects of probiotic supplementation on lean body mass, strength, and power, and health indicators in resistance trained males: a pilot study. J Int Soc Sports Nutr. (2014) 11:1-2. doi: 10.1186/1550-2783-11-S1-P38

70. Jäger R, Shields KA, Lowery RP, De Souza EO, Partl JM, Hollmer C, et al. Probiotic Bacillus coagulans GBI-30, 6086 reduces exerciseinduced muscle damage and increases recovery. PeerJ. (2016) 4:e2276. doi: 10.7717/peerj.2276

71. Jäger R, Purpura M, Stone JD, Turner SM, Anzalone AJ, Eimerbrink MJ, et al. Probiotic Streptococcus thermophilus FP4 and Bifidobacterium breve BR03 supplementation attenuates performance and range-ofmotion decrements following muscle damaging exercise. Nutrients. (2016) 8:642. doi: 10.3390/nu8100642

72. Dong W, Wang Y, Liao S, Lai M, Peng L, Song G. Reduction in the choking phenomenon in elite diving athletes through changes in gut microbiota induced by yogurt containing Bifidobacterium animalis subsp. lactis BB-12: A Quasi Experimental Study. Microorganisms. (2020) 8:597. doi: 10.3390/microorganisms8040597

73. Townsend JR, Bender D, Vantrease WC, Sapp PA, Toy AM, Woods CA, et al. Effects of Probiotic (Bacillus subtilis DE111) supplementation on immune function, hormonal status, and physical performance in division i baseball players. Sports. (2018) 6:70. doi: 10.3390/sports6030070

74. Marttinen M, Ala-Jaakkola R, Laitila A, Lehtinen MJ. Gut microbiota, probiotics and physical performance in athletes and physically active individuals. Nutrients. (2020) 12:2936. doi: 10.3390/nu12102936

75. Przewłócka K, Folwarski M, Kazmierczak-Siedlecka K, Skonieczna-Zydecka K, Kaczor JJ. Gut-Muscle AxisExists and May Affect Skeletal Muscle Adaptation to Training. Nutrients. (2020) 12:1451. doi: 10.3390/nu12051451

76. Wosinska L, Cotter PD, O'Sullivan O, Guinane C. The Potential Impact of Probiotics on the Gut Microbiome of Athletes. Nutrients. (2019) 11:2270. doi: 10.3390/nu11102270

77. Agans RT, Giles GE, Goodson MS, Karl JP, Leyh S, Mumy KL, et al. Evaluation of probiotics for warfighter health and performance. Frontiers in Nutrition. (2020) 7(70). doi: 10.3389/fnut.2020.00070

78. Jäger R, Mohr AE, Carpenter KC, Kerksick CM, Purpura M, Moussa A, et al. International society of sports nutrition position stand: probiotics. J Int Soc Sports Nutr. (2019) 16:62-. doi: 10.1186/s12970-019-0329-0

79. Suez J, Zmora N, Zilberman-Schapira G, Mor U, Dori-Bachash M, Bashiardes S, et al. Post-antibiotic gut mucosal microbiome reconstitution is impaired by probiotics and improved by autologous FMT. Cell. (2018) 174:1406-23. e16. doi: 10.1016/j.cell.2018.08.047

80. Zmora N, Zilberman-Schapira G, Suez J, Mor U, Dori-Bachash M, Bashiardes $S$, et al. Personalized gut mucosal colonization resistance to empiric probiotics is associated with unique host and microbiome features. Cell. (2018) 174:1388-405. e21. doi: 10.1016/j.cell.2018.08.041

81. Nyangale EP, Farmer S, Cash HA, Keller D, Chernoff D, Gibson GR. Bacillus coagulans GBI-30, 6086 modulates Faecalibacterium prausnitzii in older men and women. J Nutr. (2015) 145:1446-52. doi: 10.3945/jn.114. 199802

82. Keller D, Van Dinter R, Cash H, Farmer S, Venema K. Bacillus coagulans GBI-30, 6086 increases plant protein digestion in a dynamic, computercontrolled in vitro model of the small intestine (TIM-1). Benef Microbes. (2017) 8:491-6. doi: 10.3920/BM2016.0196

83. Jäger R, Zaragoza J, Purpura $M$, Iametti $S$, Marengo $M$, Tinsley GM, et al. Probiotic administration increases amino acid absorption from plant protein: a placebo-controlled, randomized, double-blind, multicenter, crossover study. Probiot Antimicrob Proteins. (2020) 12:13309. doi: 10.1007/s12602-020-09656-5

84. Stecker RA, Moon JM, Russo TJ, Ratliff KM, Mumford PW, Jäger R, et al. Bacillus coagulans GBI-30, 6086 improves amino acid absorption from milk protein. Nutr Metab (Lond). (2020) 17:93-. doi: 10.1186/s12986-020-00515-2 
85. Heffernan O. Sustainability: a meaty issue. Nature. (2017) 544:s1820. doi: $10.1038 / 544$ S18a

86. Tang JE, Moore DR, Kujbida GW, Tarnopolsky MA, Phillips SM. Ingestion of whey hydrolysate, casein, or soy protein isolate: effects on mixed muscle protein synthesis at rest and following resistance exercise in young men. $J$ Appl Physiol. (2009) 107:987-92. doi: 10.1152/japplphysiol.00076.2009

87. Leser S. The 2013 FAO report on dietary protein quality evaluation in human nutrition: Recommendations and implications. Nutr Bull. (2013) 38:421-8. doi: $10.1111 /$ nbu. 12063

88. Consultation FE. Dietary protein quality evaluation in human nutrition. FAO Food Nutr. (2011) 92:1-66.

89. Gilani S, Tomé D, Moughan P, Burlingame B. Report of a SubCommittee of the 2011 FAO Consultation on "Protein Quality Evaluation in Human Nutrition."

90. Gilani S, Wu Xiao C, Cockell KA. Impact of antinutritional factors in food proteins on the digestibility of protein and the bioavailability of amino acids and on protein quality. Br J Nutr. (2012) 108(Suppl. 2):s31532. doi: 10.1017/S0007114512002371

91. Seiquer I, Díaz-Alguacil J, Delgado-Andrade C, López-Frías M, Muñoz Hoyos A, Galdó G, et al. Diets rich in Maillard reaction products affect protein digestibility in adolescent males aged 11-14 y. Am J Clin Nutr. (2006) 83:1082-8. doi: 10.1093/ajcn/83.5.1082

92. Nyakayiru J, van Lieshout GA, Trommelen J, van Kranenburg J, Verdijk LB, Bragt MC, et al. The glycation level of milk protein strongly modulates post-prandial lysine availability in humans. Br J Nutr. (2020) 123:54552. doi: 10.1017/S0007114519002927

93. Sanni AI, Onilude AA, Ibidapo OT. Biochemical composition of infant weaning food fabricated from fermented blends of cereal and soybean. Food Chem. (1999) 65:35-9. doi: 10.1016/S0308-8146(98)00132-0

94. Öste RE. Digestibility of processed food protein. Adv Exp Med Biol. (1991) 289:371-88. doi: 10.1007/978-1-4899-2626-5_27

95. Gibson RS, Perlas L, Hotz C. Improving the bioavailability of nutrients in plant foods at the household level. Proc Nutr Soc. (2006) 65:1608. doi: 10.1079/PNS2006489

96. Koopman R, Crombach N, Gijsen AP, Walrand S, Fauquant J, Kies AK, et al. Ingestion of a protein hydrolysate is accompanied by an accelerated in vivo digestion and absorption rate when compared with its intact protein. Am J Clin Nutr. (2009) 90:106-15. doi: 10.3945/ajcn.2009.27474

97. Wilkinson DJ, Piasecki M, Atherton PJ. The age-related loss of skeletal muscle mass and function: measurement and physiology of muscle fibre atrophy and muscle fibre loss in humans. Ageing Res Rev. (2018) 47:12332. doi: 10.1016/j.arr.2018.07.005

98. Mitchell WK, Phillips BE, Williams JP, Rankin D, Lund JN, Wilkinson DJ, et al. The impact of delivery profile of essential amino acids upon skeletal muscle protein synthesis in older men: clinical efficacy of pulse vs. bolus supply. Am J Physiol Endocrinol Metab. (2015) 309:E450E7. doi: 10.1152/ajpendo.00112.2015

99. Moore DR, Churchward-Venne TA, Witard O, Breen L, Burd NA, Tipton KD, et al. Protein ingestion to stimulate myofibrillar protein synthesis requires greater relative protein intakes in healthy older versus younger men. J Gerontol Ser A Biomed Sci Med Sci. (2015) 70:5762. doi: 10.1093/gerona/glu103

100. Bauer J, Biolo G, Cederholm T, Cesari M, Cruz-Jentoft AJ, Morley JE, et al. Evidence-based recommendations for optimal dietary protein intake in older people: a position paper from the PROT-AGE Study Group. J Am Med Dir Assoc. (2013) 14:542-59. doi: 10.1016/j.jamda.2013.05.021

101. Giezenaar C, Chapman I, Luscombe-Marsh N, Feinle-Bisset C, Horowitz M, Soenen S. Ageing is associated with decreases in appetite and energy intake-a meta-analysis in healthy adults. Nutrients. (2016) 8:28. doi: $10.3390 /$ nu 8010028

102. Kavanagh K, Hsu F-C, Davis AT, Kritchevsky SB, Rejeski WJ, Kim S. Biomarkers of leaky gut are related to inflammation and reduced physical function in older adults with cardiometabolic disease and mobility limitations. Geroscience. (2019) 41:923-33. doi: 10.1007/s11357-019-00112-Z

103. Wilson QN, Wells M, Davis AT, Sherrill C, Tsilimigras MC, Jones $\mathrm{RB}$, et al. Greater microbial translocation and vulnerability to metabolic disease in healthy aged female monkeys. Sci Rep. (2018) 8:1-10. doi: 10.1038/s41598-018-29473-9
104. Thevaranjan N, Puchta A, Schulz C, Naidoo A, Szamosi J, Verschoor CP, et al. Age-associated microbial dysbiosis promotes intestinal permeability, systemic inflammation, and macrophage dysfunction. Cell Host Microbe. (2017) 21:455-66. doi: 10.1016/j.chom.2017.03.002

105. Fransen F, van Beek AA, Borghuis T, Aidy SE, Hugenholtz F, van der Gaast-de Jongh C, et al. Aged gut microbiota contributes to systemical inflammaging after transfer to germ-free mice. Front Immunol. (2017) 8:1385. doi: 10.3389/fimmu.2017.01385

106. Spychala MS, Venna VR, Jandzinski M, Doran SJ, Durgan DJ, Ganesh BP, et al. Age-related changes in the gut microbiota influence systemic inflammation and stroke outcome. Ann Neurol. (2018) 84:23-36. doi: 10.1002/ana.25250

107. Mitchell E, Davis A, Brass K, Dendinger M, Barner R, Gharaibeh $\mathrm{R}$, et al. Reduced intestinal motility, mucosal barrier function, and inflammation in aged monkeys. J Nutr Health Aging. (2017) 21:35461. doi: 10.1007/s12603-016-0725-y

108. Qi Y, Goel R, Kim S, Richards EM, Carter CS, Pepine CJ, et al. Intestinal permeability biomarker zonulin is elevated in healthy aging. J Am Med Dir Assoc. (2017) 18:810. doi: 10.1016/j.jamda.2017.05.018

109. Sturgeon C, Fasano A. Zonulin, a regulator of epithelial and endothelial barrier functions, and its involvement in chronic inflammatory diseases. Tissue barriers. (2016) 4:e1251384. doi: 10.1080/21688370.2016.1251384

110. Buford TW, Carter CS, VanDerPol WJ, Chen D, Lefkowitz EJ, Eipers $\mathrm{P}$, et al. Composition and richness of the serum microbiome differ by age and link to systemic inflammation. Geroscience. (2018) 40:25768. doi: 10.1007/s11357-018-0026-y

111. Valentini L, Ramminger S, Haas V, Postrach E, Werich M, Fischer A, et al. Small intestinal permeability in older adults. Physiol Rep. (2014) 2:e00281. doi: 10.1002/phy2.281

112. Bruunsgaard $\mathrm{H}$, Andersen-Ranberg $\mathrm{K}$, vB Hjelmborg J, Pedersen BK, Jeune B. Elevated levels of tumor necrosis factor alpha and mortality in centenarians. Am J Med. (2003) 115:27883. doi: 10.1016/S0002-9343(03)00329-2

113. Maynard C, Weinkove D. The gut microbiota and ageing. Subcell Biochem. (2018) 90:351-71. doi: 10.1007/978-981-13-2835-0_12

114. Cesari M, Penninx BW, Pahor M, Lauretani F, Corsi AM, Williams GR, et al. Inflammatory markers and physical performance in older persons: the InCHIANTI study. J Gerontol Ser A Biol Sci Med Sci. (2004) 59:2428. doi: 10.1093/gerona/59.3.M242

115. Choi Y, Kwon Y, Kim D-K, Jeon J, Jang SC, Wang T, et al. Gut microbe-derived extracellular vesicles induce insulin resistance, thereby impairing glucose metabolism in skeletal muscle. Sci Rep. (2015) 5:15878. doi: $10.1038 /$ srep 15878

116. Cani PD, Amar J, Iglesias MA, Poggi M, Knauf C, Bastelica D, et al. Metabolic endotoxemia initiates obesity and insulin resistance. Diabetes. (2007) 56:1761-72. doi: 10.2337/db06-1491

117. Andreasen AS, Kelly M, Berg RMG, Møller K, Pedersen BK. Type 2 diabetes is associated with altered NF- $\mathrm{B}$ DNA binding activity, JNK phosphorylation, and AMPK phosphorylation in skeletal muscle after LPS. PLoS ONE. (2011) 6:e23999. doi: 10.1371/journal.pone.0023999

118. Liang H, Hussey SE, Sanchez-Avila A, Tantiwong P, Musi N. Effect of lipopolysaccharide on inflammation and insulin action in human muscle. PLoS ONE. (2013) 8(5). doi: 10.1371/journal.pone.0063983

119. Lamprecht M, Bogner S, Schippinger G, Steinbauer K, Fankhauser F, Hallstroem S, et al. Probiotic supplementation affects markers of intestinal barrier, oxidation, and inflammation in trained men; a randomized, double-blinded, placebo-controlled trial. J Int Soc Sports Nutr. (2012) 9:113. doi: 10.1186/1550-2783-9-45

120. Lee S, Kirkland R, Grunewald ZI, Sun Q, Wicker L, de La Serre CB. Beneficial effects of non-encapsulated or encapsulated probiotic supplementation on microbiota composition, intestinal barrier functions, inflammatory profiles, and glucose tolerance in high fat fed rats. Nutrients. (2019) 11:1975. doi: 10.3390/nu11091975

121. Laval L, Martin R, Natividad J, Chain F, Miquel S, De Maredsous CD, et al. Lactobacillus rhamnosus CNCM I-3690 and the commensal bacterium Faecalibacterium prausnitzii A2-165 exhibit similar protective effects to induced barrier hyper-permeability in mice. Gut microbes. (2015) 6:19. doi: 10.4161/19490976.2014.990784 
122. Wang J, Ji H, Wang S, Liu H, Zhang W, Zhang D, et al. Probiotic Lactobacillus plantarum promotes intestinal barrier function by strengthening the epithelium and modulating gut microbiota. Front Microbiol. (2018) 9:1953. doi: 10.3389/fmicb.2018. 01953

123. Van Hemert S, Verwer J, Schütz B. Clinical studies evaluating effects of probiotics on parameters of intestinal barrier function. Adv Microbiol. (2013) 3:212-22. doi: 10.4236/aim.2013.32032

124. Ticinesi A, Lauretani F, Milani C, Nouvenne A, Tana C, Del Rio D, et al. Aging gut microbiota at the cross-road between nutrition, physical frailty, and sarcopenia: is there a gut-muscle axis? Nutrients. (2017) 9:1303. doi: 10.3390/nu9121303

125. den Besten G, van Eunen K, Groen AK, Venema K, Reijngoud D-J, Bakker $\mathrm{BM}$. The role of short-chain fatty acids in the interplay between diet, gut microbiota, and host energy metabolism. J Lipid Res. (2013) 54:232540. doi: 10.1194/jlr.R036012

126. Nagpal R, Wang S, Ahmadi S, Hayes J, Gagliano J, Subashchandrabose $S$, et al. Human-origin probiotic cocktail increases short-chain fatty acid production via modulation of mice and human gut microbiome. Sci Rep. (2018) 8:1-15. doi: 10.1038/s41598-018-30114-4

127. Matsumoto M, Kibe R, Ooga T, Aiba Y, Kurihara S, Sawaki E, et al. Impact of intestinal microbiota on intestinal luminal metabolome. Sci Rep. (2012) 2:1-10. doi: 10.1038/srep00233

128. Gao Z, Yin J, Zhang J, Ward RE, Martin RJ, Lefevre M, et al. Butyrate improves insulin sensitivity and increases energy expenditure in mice. Diabetes. (2009) 58:1509-17. doi: 10.2337/db08-1637
129. Walsh ME, Bhattacharya A, Sataranatarajan K, Qaisar R, Sloane L, Rahman $\mathrm{MM}$, et al. The histone deacetylase inhibitor butyrate improves metabolism and reduces muscle atrophy during aging. Aging Cell. (2015) 14:95770. doi: 10.1111/acel.12387

130. Nations U. World Population Prospects: The 2017 Revision, Key Findings and Advance Tables. Department of Economics and Social Affairs PD, editor. New York, NY: United Nations. (2017).

131. Commision E. Plant-Based Foods in Europe: How Big Is the Market? CORDIS EU Results: EU COMMISION. (2020). Available online at: https://cordis. europa.eu/article/id/429495- europe-s-plant-based-food-industry-showsrecord-level-growth

Conflict of Interest: EM is in receipt of a Ph.D. studentship co-funded by the Irish Research Council and Kerry.

The remaining authors declare that the research was conducted in the absence of any commercial or financial relationships that could be construed as a potential conflict of interest.

Copyright (c) 2021 de Marco Castro, Murphy and Roche. This is an open-access article distributed under the terms of the Creative Commons Attribution License (CC $B Y)$. The use, distribution or reproduction in other forums is permitted, provided the original author(s) and the copyright owner(s) are credited and that the original publication in this journal is cited, in accordance with accepted academic practice. No use, distribution or reproduction is permitted which does not comply with these terms. 